\title{
School Based Dengue Control Programme; Impact of awareness and training on control measures
}

\author{
S.M Arnold \\ Ministry of Health, Sri Lanka \\ E Mail: mahendra_arnold@yahoo.com \\ DOI: 10.31364/SCIRJ/v8.i10.2020.P1020814 \\ http://dx.doi.org/10.31364/SCIRJ/v8.i10.2020.P1020814
}

\begin{abstract}
Background
ABSTRACT

School children are a captive population, where positive practices can be cultured in them easily. If the school children are made knowledgeable about the disease and the control methods available the students tend to keep their school and domestic environment clean and dengue free. They act as messengers to carry the message of dengue prevention to the community, thereby actively participate in dengue control and prevention. This research was conducted with the aim of assessing the effect of the School based dengue control programme facilitated with awareness and training in improving the dengue control activities of school children.
\end{abstract}

\section{Methods}

This study covered ten schools each from categories of schools with and without an ongoing School Dengue Programme. Total of the 400 students in year 10 participated, with 200 students from each category of school. Self-administered questionnaire was used to assess the knowledge and attitudes. A checklist for assessment of practices in the school premises was used as study instruments. In the Schools with School based Dengue Control programme, it was enhanced through activation of School Health Clubs. Educational intervention was made through awareness programmes, video presentation on dengue control activities and practical training in the school environment to identify potential mosquito breeding sites and destroy them.

\section{Results}

The study found that $95.5 \%$ of students in schools with school dengue programme had an overall good level of knowledge compared to $60.5 \%$ of students in schools without the programme The difference was statistically significant $(\mathrm{P}<0.001)$ in knowledge in areas such as identification of clinical signs and symptoms, complications and knowledge on exposure where the former had a good level of knowledge compared to the latter. In schools with ongoing programme there were more students with positive attitudes regarding control measures and responsibility. This was statistically significant $(\mathrm{P}<0.0001)$. The dengue control practices in the school premises were satisfactory in schools with an ongoing school dengue control programme. It was found that in few schools even though there was a dengue control programme the mosquito control practices were poor.

\section{Conclusion}

School based dengue control programme with the involvement of School Health Clubs and facilitated by awareness and training was successful in improving knowledge, attitudes and the dengue control practices of the school children.

Key words: Dengue Control Programme, School Health Clubs, Training, Awareness

\section{INTRODUCTION}

Dengue is a major public health problem in Sri Lanka and globally. It is one of the human viral diseases transmitted by arthropod vectors. It is estimated that 390 million dengue virus infections occurs annually of which 96 million manifest clinically (1). Around 3.9 billion people are at risk of infection with dengue viruses and Asia carries a 70\% of actual burden (2).

Dengue is a severe, flu-like illness. It affects infants, young children and adults and symptoms lasts for around 2-7 days. It has an incubation period of 4-10 days after the bite from an infected mosquito (3). Dengue virus is transmitted by female mosquitoes mainly of the species Aedes aegypti and to a lesser extent, Ae. albopictus. In some regions in the world (South America, Asia) other Aedes species such as Aedes albopictus, Aedes polynesiensis and Aedes scytellaris are also involved.(4). The reservoir of infection is both man and mosquito. The transmission cycle is "man-mosquito-man". The Aedes mosquito becomes infective by feeding on a patient. The extrinsic incubation period (EIP) which is the time it takes from ingesting the virus to actual transmission to a new host is about $8-12$ days when the ambient temperature is between $25-28^{\circ} \mathrm{C}(5-7)$.

$$
\text { www.scirj.org }
$$

(C) 2020, Scientific Research Journal

http://dx.doi.org/10.31364/SCIRJ/v8.i10.2020.P1020814

This publication is licensed under Creative Commons Attribution CC BY. 
Urbanisation has been a major factor in the spread of the species. Any major disturbance in human ecology, especially in urban areas in recent years has served to amplify populations of Aaedes aegypti. Examples of such disturbances include rapid growth of cities, population explosions, a steady deterioration of the environment and increase in the number of water-retaining waste containers and debris. Aedes albopictus is primarily a species found in forested areas and where there is natural vegetation. The species has now adapted to urban environment and are found in urban and semi urban areas in increasing numbers (8-10).

Aedes mosquito which transmits dengue virus breeds in collections of clean water, mostly in water containers, coconut shells, water storage tanks, discarded tyres, tins etc. Anything that will retain water in tropics can be transformed into a potential development site for Aedes mosquito. The peak period of spread is following monsoon rain where breeding sites and containers are favourable for breeding. The disease is often closely associated with poor environmental sanitation, slums, urbanization and inadequate water supplies. The female mosquito feeds on human beings and its usual flight range is about 50 - 100 meters, but sometimes may even be about one to two kilometres (12).

There is no effective vaccine available for dengue at present. Currently vaccine trials are being held in Thailand and some other countries. The main method of prevention of dengue is to control the mosquito vector. Destroying the breeding places and keeping the environment clean can achieve vector control. This can be achieved only by active participation and support of the community to eliminate mosquito-breeding sites. Some of the important aspects that need attention are to improve knowledge, change negative attitudes and cultivate desirable practices of dengue control in the community.

Dengue was endemic in Sri Lanka from the beginning of the $20^{\text {th }}$ century (13). From 1965 where the first case of DHF was detected and up to 1988 only a few cases were reported each year in Sri Lanka. The first major outbreak of DF/DHF occurred in the year 1989 with 203 clinically diagnosed cases of DF/DHF. Regular epidemics of DF/DHF have been occurring in Sri Lanka since 1989 (13-15). A dengue epidemic of unexpected magnitude occurred in Sri Lanka in 2017 with a total of 186,101 suspected cases and 440 denguerelated deaths occurring (16).

A Presidential Task Force was appointed in 1996 to strengthen community based integrated prevention of dengue with emphasis of school-based approach. This school based dengue control programme is carried out with the coordination of the Health and Education Ministries. School children are a captive population, where positive practices can be cultured in them easily. The school children are made knowledgeable about the disease and the control methods available. The students keep their school and domestic environment clean and dengue free. They act as messengers to carry the message of dengue prevention to the community, thereby actively participate in dengue control and prevention.

School Health Clubs play a major role in implementing this school based dengue control programme. Dengue control activities are carried out through the School Health Clubs where they are available. Health and Educational authorities guide the students and they carry out dengue control programmes in the schools and the community.

\section{METHODS}

The study was conducted at the Medical Officer of Health (MOH) Dehiwela. This area was selected for this study since it is a highly populated urban area with high potentials for mosquito breeding. There have been many dengue patients reported during the past few years in this region and the incidence is rising. There are large number of schools in this area where some schools have an ongoing School Based Dengue Control Programme.

The study population was the year 10 students and the school premises of selected schools in the Dehiwela MOH area. There are total of 39 schools in the Dehiwela area and 32 schools have year 10 classes. Schools were categorised into two groups; schools having school based dengue programmes and schools not having the programmes. Ten schools each from the two categories were randomly selected.

The knowledge, attitudes and practices among year 10 students on dengue and dengue control programme was assessed using a pre tested self-administered questionnaire. A checklist was used to assess the school environment regarding dengue control practices. In Schools with dengue control programmes the Schools Health Clubs were used to impart knowledge and train students on dengue control activities. In schools of the intervention group where the School Health Clubs were not functioning, steps were taken to reactivate the school health clubs. Educational intervention was made through awareness programmes, video presentation on dengue control activities and practical training in the school environment to identify potential mosquito breeding sites and destroy them. The Medical Officers of Health and Public Health Inspectors conducted the awareness and training. The public health staff were trained on 
dengue control methods through in-service training. Two hundred students each from the intervention and control groups were selected for the study. The intervention was not carried out in the control group which did not have ongoing control programme.

The year 10 students were selected as the sample for the study since year 11, 12 and 13 students are engaged in G.C.E. Ordinary Level and G.C.E. Advanced Level examinations and it was ethically not acceptable to distract them from their routine study periods, which were used for the study. The lower grades were not selected since it was assumed that they might not be mature enough to answer the self-administered questionnaire. The year 10 students were selected since they were free from any major examinations and were mature enough and knowledgeable to answer a self-administered questionnaire. It was found that in some schools minimum number in a year 10 class was 20 students. Therefore, it was decided to select 20 students from each school in order to have an equal representation from all the selected schools. The students were selected using simple random sampling technique. If there were more than one class of year 10 in the selected school a single class was selected randomly. In the selected class if there were more than 20 students, 20 students were selected by using random number tables. The numbered attendance register of the class was used as the sampling frame. The required sample of 400 students were selected from 20 schools using the above sampling procedure.

\section{RESULTS}

\section{Knowledge on dengue}

Of students in schools with an ongoing dengue programme shows that $95.5 \%$ had a good overall knowledge on dengue and dengue control compared to $60.5 \%$ of students in the other category. It is observed that $15 \%$ of students without a dengue programme had a poor knowledge, where as it was only $1 \%$ in other category. The mean knowledge score in schools with dengue proramme was 80.4 compared to 69.6 in schools without the programme. The differences were statistically significant $(\mathrm{p}<0.001)$.

Table 1: Distribution of students by overall knowledge on dengue

\begin{tabular}{lcrcrc}
\hline Knowledge & \multicolumn{2}{c}{$\begin{array}{c}\text { Students in Schools } \\
\text { with Dengue Programme }\end{array}$} & \multicolumn{2}{c}{$\begin{array}{c}\text { Students in Schools without Dengue } \\
\text { Programme }\end{array}$} & Significance \\
\cline { 2 - 5 } & No & $\%$ & No & 15.0 & \\
\hline Poor & 02 & 1.0 & 30 & 24.5 & $\mathrm{P}<0.001$ \\
Satisfactory & 07 & 3.5 & 49 & 60.0 & 100.0 \\
Good & 191 & 95.5 & 121 & 200 & \\
Total & 200 & 100.0 & & & \\
\hline
\end{tabular}

\section{Attitudes on dengue control}

In order to carry out a successful programme the participants should have positive attitude towards the activities of the programme. In the school based dengue control programme one of the objectives is to cultivate desirable attitudes on dengue control in the school children. In this programme much emphasis is focused on to develop the students attitudes in areas such as, responsibility of carrying out control activities, place and time period of implementation, sharing of knowledge with the community, participation and usefulness of the control programme. Students develop these positive attitudes by actively participating in dengue control programmes which are carried out, both in school and the community. The students attitudes were assessed by using a Likert Scale attitude questionnaire. In schools with ongoing programme there were more students with positive attitudes regarding control measures and responsibility. This was statistically significant $(\mathrm{P}<0.001)$

Table 2: Distribution of overall attitudes on dengue control

\begin{tabular}{|c|c|c|c|c|c|}
\hline \multirow[t]{2}{*}{ Attitude } & \multicolumn{2}{|c|}{$\begin{array}{c}\text { Students in Schools } \\
\text { with Dengue Programme }\end{array}$} & \multicolumn{2}{|c|}{$\begin{array}{c}\text { Students in Schools without Dengue } \\
\text { Programme }\end{array}$} & \multirow[t]{2}{*}{ Significance } \\
\hline & No & $\%$ & No & $\%$ & \\
\hline Positive & 187 & 93.5 & 163 & 81.5 & \\
\hline Negative & 06 & 3.0 & 21 & 10.5 & $\mathrm{P}<0.001$ \\
\hline Neutral & 07 & 3.5 & 16 & 8.0 & \\
\hline Total & 200 & 100.0 & 200 & 100.0 & \\
\hline
\end{tabular}

\section{Practices on dengue control}


The actual practices were assessed by calculating the larval indexes. The Potential Container Index (PI) range from $21-68$ in schools with Dengue Control Programme and from 30 - 60 in schools without Dengue Control Programme. High and low indexes were found in both categories of schools. Container Index was zero in 19 out of 20 schools included in the study. Aedes aegypti larvae were isolated in one school without the Dengue Control Programme with a Container Index of 8.3.

Table 3: Distribution by larval indices in school premises

\begin{tabular}{lccccc}
\hline \multicolumn{2}{c}{ Schools with Dengue Programme } & \multicolumn{3}{c}{ Schools without Dengue Programme } \\
\hline School No & $\begin{array}{c}\text { Potential } \\
\text { Container Index }\end{array}$ & $\begin{array}{c}\text { Container } \\
\text { Index }\end{array}$ & School No & $\begin{array}{c}\text { Potential } \\
\text { Container Index }\end{array}$ & $\begin{array}{c}\text { Container } \\
\text { Index }\end{array}$ \\
\hline 1 & 21 & 00 & 1 & 50 & 00 \\
2 & 68 & 00 & 2 & 30 & 00 \\
3 & 53 & 00 & 3 & 45 & 00 \\
4 & 30 & 00 & 4 & 59 & 8.3 \\
5 & 22 & 00 & 5 & 40 & 00 \\
6 & 43 & 00 & 6 & 46 & 00 \\
7 & 41 & 00 & 7 & 37 & 00 \\
8 & 52 & 00 & 8 & 55 & 00 \\
9 & 42 & 00 & 9 & 33 & 00 \\
10 & 36 & 00 & 10 & 60 & 00 \\
\hline
\end{tabular}

In order to observe the consistency of the control activities, the potential breeding sites were accounted, during two observations three months apart. Mean Potential Container Index had decreased on the second observation in schools with Dengue Control Programme from 42.1 to 39.6 , where as it has increased from 44.2 to 46.9 in the other category.

\section{DISCUSSION}

Dengue has become an important public health problem in Sri Lanka, with rising levels of morbidity and mortality. In the recent past epidemics of dengue have occurred annually and high priority should be given to control this disease. In community-based dengue control programmes, educating the public on dengue control methods is done at the initial stages to make the public knowledgeable and get their support for these control activities.

The objective of health education activities is to make people aware of the threat that dengue poses to their health and to indicate to them how they can reduce this threat by eliminating or controlling domestic mosquito breeding sites. In dengue control activities knowledge, attitudes and practices of the community on dengue and dengue control programme is vital to sustain an effective control programme. The school students are being involved in dengue control activities and they act as messengers to take the message of dengue and dengue control methods to the community. Since school children are a captive population who are growing up, knowledge, positive attitudes and practices can be developed in them. School children will be a vital segment in the dengue control programmes. These activities are currently done through the school based dengue control programmes conducted in schools with the involvement of the Health and Education sector.

It is important to have a good overall knowledge on the disease. A student having good knowledge on disease transmission and control can contribute effectively in dengue control in the community. Therefore, it is important to have a good overall knowledge for effective control. This study found that $95.5 \%$ of students in schools with dengue programme and $60.5 \%$ of students in schools without school dengue programme had an overall good knowledge. Further analysis showed that the mean score (80.4\%) obtained by students in schools with dengue programme is high compared to the mean score of $69.6 \%$ in the other category, which is apparently not unusual. The School Health Clubs can act as facilitators to the dengue control programme by conducting dengue control activities as a part of the Health Club activities. Since many schools have School Health Clubs or at least Health Societies, it would be ideal to incorporate dengue control programmes with School Health Clubs.

Attitude is an opinion or way of thinking and behaviour. In school dengue programme activities efforts are taken to change the way the students look at dengue control, especially their role and responsibilities in the school and the community. It is this desirable attitude coupled with good knowledge that has to be transformed into practices of dengue control. To implement a successful dengue control programme there should be positive attitudes towards the control programme in the participants. Even though there is good knowledge if the attitudes are not favourable it will hamper the successful implementation of the control programme. The overall attitude was assessed by calculating the percentages of student's attitudes towards the main components of the school dengue 
programme. Majority of students in both categories have a good overall positive attitude on activities of the school dengue control programme.

Good knowledge and positive attitudes do not ensure a good practice, and has to be transformed into practices to achieve set objectives. Practices on dengue control were assessed in the school premises with regard to presence of potential mosquito breeding sites. This gave an overview of the efforts taken to keep the school premises free of dengue. In comparison of two categories of schools the Mean Potential Container Index (average number of potential breeding sites per premises) was higher in the schools without the dengue control programme, than in schools with school dengue programme. Dengue control activities should be carried out throughout the year to arrest the mosquito breeding. This is necessary since mosquito-breeding containers are continuously produced and released to the environment due to activities of the community. If mosquito control is done only during an epidemic, potential containers will get accumulated during the other period and the mosquito density will rise when ideal climatic conditions prevail.

Further analysis of the Potential Container Index (number of potential breeding sites per premises) for each school it was found that even though the Potential Container Indexes were generally satisfactory in schools with the ongoing school dengue programme, few schools had higher values and some schools in the schools without dengue programme category had low values. This may be an indication that the good knowledge and attitudes in some schools have not been put into practice. Larval densities give a good indication of mosquito control in environment. Various indexes such as Bretaue Index, Container Index, and House Index are used for this purpose. In this study Container Index (percentage of water holding containers infested with larvae or pupae) was used to assess the larval densities in the school premises. There was one school where Aedes aegypti was isolated. This school did not have an on going school dengue programme, little or no

\section{CONCLUSIONS}

This study revealed that students in schools with an ongoing School Dengue Programme coupled with awareness and training carried out by trained public health staff had a good knowledge and desirable attitudes than students in schools without the programme. In observing the practices on dengue control in the school premises the schools with the programme on average had lesser number of potential mosquito breeding sites than the schools without the programme. These findings indicate that the ongoing School Dengue Programme has an effect on dengue control activities among the school children and should be further strengthened.

\section{REFERENCE}

1. Bhatt, S., et al., The global distribution and burden of dengue. Nature, 2013:496 (7446): p. 504-507.

2. Brady, O.J., et al., Refining the global spatial limits of dengue virus transmission by evidence-based consensus. PLOS Neglected Tropical Diseases, 2012:. 6(8): p. 1760.

3. World Health, O., Dengue: Guidelines for Diagnosis, Treatment, Prevention and Control. Dengue: Guidelines for Diagnosis, Treatment, Prevention and Control. 2009, Geneva: World Health Organization. 1-147.

4. World Health Organization. Dengue and severe dengue. 2020, Geneva: World Health Organization. Available at: https://www.who.int/news-room/fact-sheets/detail/dengue-and-severe-dengue

5. Tjaden, N.B., et al., Extrinsic Incubation Period of Dengue: Knowledge, Backlog, and Applications of Temperature Dependence. Plos Neglected Tropical Diseases, 2013: 7(6): p. 5.

6. Siler, J.F., M.W. Hall, M.W, Hitchens, A.P. Dengue: Its history, epidemiology, mechanism of transmission, etiology, clinical manifestations, immunity and prevention. 1926, Manila: Bureau of Science.

7. Watts, D.M., et al., Effect of Temperature on the vector efficiency of Aedes aegypti for Dengue 2 virus. American Journal of Tropical Medicine and Hygiene, 1987. 36(1): p. 143-152.

8. Duane J. Gubler. Dengue, Urbanization and Globalization: The Unholy Trinity of the $21^{\text {st }}$ Century. Trop Med Health. 2011 Dec; 39(4 Suppl): 3-11

9. Akhtar R., Gupta P.T., Srivastava A.K. Urbanization, Urban Heat Island Effects and Dengue Outbreak in Delhi. In: Akhtar R. (eds) Climate Change and Human Health Scenario in South and Southeast Asia. Advances in Asian Human-Environmental Research. 2016, Springer, Cham. https://doi.org/10.1007/978-3-319-23684-1_7

10. Ren H, Wu W, Li T, Yang Z. Urban villages as transfer stations for dengue fever epidemic: A case study in the Guangzhou, China. PLOS Neglected Tropical Diseases, 2019: 13(4)

11. Messina, J.P., Brady, O.J., Golding, N. et al. The current and future global distribution and population at risk of dengue. Nat Microbiol 4, 1508-1515 (2019). https://doi.org/10.1038/s41564-019-0476-8

www.scirj.org

(C) 2020, Scientific Research Journal

http://dx.doi.org/10.31364/SCIRJ/v8.i10.2020.P1020814

This publication is licensed under Creative Commons Attribution CC BY. 
12. Piet F.M.Verdonschot, Anna A.Besse-Lototskaya. Flight distance of mosquitoes (Culicidae): A metadata analysis to support the management of barrier zones around rewetted and newly constructed wetlands, Limnologica, 2014 (45):69- 79

13. Sirisena, P.D.N.N, Noordeen, F. Evolution of dengue in Sri Lanka-changes in the virus, vector, and climate, International Journal of Infectious Diseases, 2014 (19): 6-12

14. Vitarana, U.T, Jayasekera, N., Withane, N., Gubler, D.J. Finding the cause of dengue hemorrhagic fever outbreaks in Sri Lanka., Arbovirus Research in Australia, 1993 (6):. 125-129

15. De Silva, A.M., Sivananthan, K, Withana, N, Vorndam, V, Gubler D.J. Dengue 3 virus is responsible for recent epidemics of dengue hemorrhagic fever in Sri Lanka, Annual Meeting of the American Society for Tropical Medicine and Hygiene, San Juan, Puerto Rico (1998)

16. Tissera HA, Jayamanne B, Raut R, et al. Severe Dengue Epidemic, Sri Lanka, 2017. Emerging Infectious Diseases. 2020;26(4):682-691. doi:10.3201/eid2604.190435. 